\title{
Inflammation, infection, and allergy of upper airways: new insights from national and real-world studies
}

\author{
Attilio Varricchio ${ }^{1}$, Ignazio La Mantia ${ }^{2}$, Francesco Paolo Brunese ${ }^{3}$ and Giorgio Ciprandi ${ }^{*}$ (D)
}

\begin{abstract}
The upper airways (UA) should be considered as a functional unit. Current functional anatomy divides URT in three, mutually dependent, "junction boxes": i) the ostio-meatal complex (OMC), ii) the spheno-ethmoidal recess (SER), and iii) the rhinopharynx (RP). Correct ventilation and effective mucociliary clearance of these sites significantly affect the healthy physiology of the entire respiratory system. The OMC, SER, and RP obstruction is the first pathogenic step in the inflammatory/infectious cascade of UA disorders. The inflammation of the respiratory mucosa is the main pathogenic factor for airway obstruction. Moreover, bacterial biofilm (a strategy modality of bacterial survival) is an important local cause of systemic antibiotic ineffectiveness, recurrent infections, and antibiotic resistance. Health microbiota guarantees UA wellness; on the contrary, dysbiosis promotes and worsens UA infections. Allergy, namely type 2 inflammation, is a common cause of UA obstruction such as promoting in turn infections. Fiberoptic endoscopy is a mandatory diagnostic tool in clinical practice. Nasal cytology, mainly concerning flow cytometry, allows defining rhinitis phenotypes so allowing a precision medicine approach. Several conventional therapeutic approaches are available, but efficacy and safety should be ever properly considered before the prescription. Also, complementary medicine plays a fruitful role in the management of UA diseases. National and real-world studies are reported and discussed as they may be useful in daily clinical practice.
\end{abstract}

Keywords: Upper airways, Allergy, Inflammation, Infection, Anatomy, Physiology, Therapy

\section{Background}

Inflammation, infection, and allergy of upper airways constitute relevant pathophysiologic mechanisms involved in the most frequent diseases in childhood. The current Commentary summarizes the pathogenic pathways of upper airways diseases (UAD) sharing these mechanisms and presents and discusses the outcomes accomplished by national studies conducted in real-world settings. The choice of selecting this kind of studies was grounded in two pragmatic assumptions. Clinical features of UAD significantly vary depending on the geographic area, therefore, findings from foreign countries cannot be simply transmuted and generalized to the local reality $[1,2]$. More and more attention had paid to the real-world studies as they may provide information more adherent to the daily practice as recruit

\footnotetext{
* Correspondence: gio.cip@libero.it

${ }^{4}$ Allergy Clinic, Casa di Cura Villa Montallegro, Via Boselli 5, 16146 Genoa, Italy Full list of author information is available at the end of the article
}

patient populations that reflect the actual situation faced by any paediatrician $[3,4]$.

\section{Functional anatomy and pathophysiology}

The airways should be globally considered a functional unit as there is strong evidence that upper airways (UA) and lower airways (LA) are closely linked $[5,6]$. UA and LA share common epidemiologic, anatomic, physiological, and pathophysiologic mechanisms. A paradigmatic example is a rhino-bronchial syndrome characterized by a spread of inflammatory and infectious events from the nose to the bronchi $[7,8]$.

In the rhino-sinus-pharyngeal district, there are three important pathophysiologic sites: i) the ostio-meatal complex (OMC), ii) the spheno-ethmoidal recess (SER), and iii) the rhino-pharynx (RP) as previously pointed out $[9,10]$. The OMC, located on the lateral wall of the nose and bordered by the low and middle turbinate, is the space where the anterior rhino-sinus system, including 
the frontal sinus, the maxillary sinus, and the anterior ethmoidal sinus, is devoted to draining the secretions.

The SER, located in the lateral wall of the nose, behind the OMC, bordered by the middle and superior turbinate, drains the posterior rhino-sinus system, including the posterior ethmoid sinus and the sphenoid sinus. The RP is the site where the post-nasal drip (such as posterior rhinorrhea) starts, it may cause descending pharyngotracheobronchitis. In the RP, the adenoids are located too. $\mathrm{RP}$ inflammation/infection is also implicated in the pathogenesis of otitis media. Moreover, RP is the site of the socalled "microbial bank" and the preferred place of bacterial biofilm [6].

Correct ventilation and effective mucociliary clearance of these three pathophysiologic junction boxes guarantee the healthy physiology of the whole respiratory system. In these sites, it occurs the filter of the inhaled air, the enrichment with nitric oxide, which in turn regulates the ciliary motility, may prevent viral replication and regulates the bronchial muscular tone [11, 12]. Therefore, the OMC, SER, and RP obstruction is the first essential pathogenic step in the cascade of inflammatory events of the rhino-sinus-pharyngeal district, often complicated by infections.

The infections may involve OMC and/or SER, causing an anterior and/or posterior rhinosinusitis [10]. Also, obstruction of OMC and/or SER causes an inflammatory reaction and posterior rhinorrhea, involving the microbial bank of the nose and pharynx, that may spread to the tubaric-tympanic-mastoid unit or lower airways. As a consequence, the rhino-bronchial syndrome occurs. Alternatively, it may involve the tympanic cavity, through the Eustachian tube, causing otitis media [13]. Also, in the case of postnasal drip, secretions (containing microbes and pro-inflammatory substances) may spread to middle-lower airways [14]. The inflammation of the respiratory mucosa is the main pathogenic factor inducing airways obstruction [15].

Infectious diseases mostly affect younger children, due to their immunological immaturity. On the contrary, inflammatory diseases and allergy mostly affect older children, adolescents, and adults [10, 14]. Acute infectious diseases have essentially a viral origin, while recurrent and chronic forms have mostly a bacterial origin. The last is due to a lack of recovery of acute infection, sustained by local (adenoids hypertrophy, anatomic, and functional malformations) and/or systemic causes (allergy, mucociliary alterations, immunological defect) [14, 15]. The biofilm is an important local cause of recurrent diseases: biofilm is a strategic modality of survival set up by bacteria and the main cause of their resistance to systemic antibiotic therapy [16]. A considerable presence of biofilm has been demonstrated in the RP of children suffering from recurrent infections of upper airways [17].
Biofilm can release, time after time, numerous bacterial colonies that cause the recurrence of respiratory infections. Both infectious and inflammatory diseases share the same pathophysiological mechanisms: the respiratory mucosa shows a wide submucosal diffusion of immuneinflammatory cells which amplify inflammation $[15,18]$. In this context, allergic inflammation may promote a vicious circle that allows the predisposition to infection recurrence and increase symptom severity.

\section{Recurrent respiratory infections}

Children with recurrent respiratory infections (RRI) represent a compelling challenge for the otolaryngologist and the paediatrician in daily practice. It was reported that at least $6 \%$ of Italian children younger than 6 years old had RRI [19]. The definition of RRI is still debated and complex. The RRI definition, proposed by an Italian panel of experts, considered a series of exclusion criteria (including absence of primary or secondary immunodeficiency, cystic fibrosis, primary ciliary dyskinesia, and airways malformations) and the presence of at least one of the following conditions: i) $>6$ annual RI; ii) one or more monthly RI from October to February; iii) $>3$ RI involving lower airways [20]. Moreover, different definitions have been proposed for each airway disorder: 1) for recurrent pharyngotonsillitis $>7$ episodes of pharyngotonsillitis in 1 year, $>5$ episodes/year for two consecutive years or $>3$ episodes/year for three consecutive years [21]; 2) for recurrent otitis media $>3$ episodes in 6 months or $>4$ episodes/year [22]; 3) for recurrent lower RI $>3$ episodes of bronchitis, bronchiolitis, or pneumonia [23]. However, differentiating lower and upper respiratory tract infections may be difficult, because symptoms and signs overlap and both may be present at the same time [24]. However, the duration and severity of RI should be also evaluated as reported in recent studies. A systematic review, concerning 5427 children, reported that common cold resolved by 15 days [25]. A Finnish study reported that the 90th percentile of the number of days in the year with respiratory disease was 98; therefore, RRI was diagnosed in children (younger than 2 years) who exceed this cut-off; the median was 9.6 RI/year [26].

Based on these issues, it is evident that RRI has a significant impact on pharmaco-economy and cause a relevant burden for both the family and society as they have frequently physician office and emergency room visits, often use antibiotics or are hospitalized for severe and complicated RI.

It has been postulated that many risk factors can account for promoting and/or causing RRI, including prematurity, preschool age (for a relative immaturity of the immune system), early attending at nursery school, air pollution, home dampness, passive exposure to tobacco 
or vape fumes, low socioeconomic level, overcrowding, and allergy [27]. Moreover, it has been hypothesized that the allergic diseases may play a particular role in promoting the RI recurrence as the physiological immune response is impaired in allergic subjects and allergic inflammation favours predisposition to infections. Type 2 immune response is defined by increased secretion of prototypical cytokines IL-4, IL-5, and IL-13 that promote, maintain, and amplify type 2 inflammation, characteristic of allergic patients [28]. However, there are different endotypes of type 2 immune response, namely, type 2 high and low, thus an adequate assessment of the immunopathological profile should be addressed in allergic patients [29]. As a consequence, subjects with allergic disorders may have a functional defect of type 1 immune response that is relevant in fighting infections. It has been reported that patients suffering from allergic diseases are prone to have more numerous and severe infections than non-allergic subjects [30, 31]. On the other hand, this situation could be reverted by allergenspecific immunotherapy [32]. Also, viral infections may increase the probability of contracting frequent RI because of the high number of circulating viruses and numerous subtypes [33]. Viral infections are predominant, but bacterial super-infections may frequently appear. Consequently, there is an overuse/misuse of antibiotics by primary care doctors that in turn induces antibiotic resistance [34, 35]. Moreover, biofilm causes frequent antibiotic unsuccess and $25-45 \%$ of children with severe RRI need surgical intervention [36, 37]. On the other hand, there is no available biomarker able to identify children at risk of RRI at present.

\section{Recurrent acute otitis media}

Acute otitis media (AOM) is an ear disease defined by signs or symptoms of acute infection [38]. AOM is the most common bacterial infection in children [39-43]. Consequently, AOM is the most common reason for antibiotic prescription in the pediatric age $[44,45]$. Almost all children experience at least one episode of AOM during childhood. Therefore, the burden of AOM is relevant both concerning the direct (healthcare expense) and indirect costs (loss of school attendance and parental workdays) and negatively impacts on quality of life of children and their parents. Moreover, antibiotic overprescription is the main cause of the increase of multidrug-resistant microbes as well as for the occurrence of adverse reactions [46, 47]. For these reasons, several guidelines on AOM management were performed to optimize management and therapy $[44,45]$.

Notably, some children with AOM tend to be otitisprone, such as to have a frequent recurrence of $\mathrm{AOM}$ (RAOM). So, the identification of factors involved in the recurrence may have a practical interest. RAOM represents, therefore, an intriguing challenge in the clinical practice for both the paediatrician and the otorhinolaryngology (ORL) specialist.

The AOM has infectious pathogenesis and is characterized by the trio: hypoacusis, fever, and otodinia. The $\mathrm{AOM}$ diagnosis requires adequate procedure and precise differential diagnosis, mainly concerning OME that has always inflammatory pathogenesis and clinical presentation is characterized by hypoacusis, never associated with fever and/or otodinia. A correct otoscopy is mandatory to differentiate viral AOM (the eardrum is flat and the bright triangle is visible) from bacterial AOM (eardrum is bulging and bright triangle is not visible). Moreover, AOM antibiotic therapy is controversial as many guidelines suggest watchful waiting for mild-moderate episodes in children $>2$ years aged. Moreover, the prevention of RAOM is overwhelmingly desirable, even though it is still debated. At present, there is no convincing evidence of preventing RAOM by the proposed treatments both conventional and not [44-47]. In this regard, the failed recovery from rhino-pharyngeal disease (as the microbial bank is not removed) may promote the AOM recurrence. To solve RAOM, topical treatments and probiotics have been proposed [44]. Therefore, as there is no convincing preventing and effective preventive treatment for RAOM, to know predictive factors for RAOM could be fruitful from a pragmatic point of view. Anyway, as very recently reported, the pragmatic approach in primary care is an overuse of broad-spectrum antibiotics [48].

\section{Adenoiditis}

Adenoids belong to the Waldeyer's ring; they are exposed to microbes, allergens, and environmental irritant factors [49]. Adenoids play a crucial role in promoting and maintaining a correct innate and adaptive immune response [50,51]. The adenoids size trend to growth during childhood, with a maximum between 2 and 5 years; after 10 years of life, they progressively reduce their volume. Recurrent respiratory infections are the most important cause of adenoidal hypertrophy ( $\mathrm{AH}$ ). $\mathrm{AH}$ has clinical relevance as large adenoids are an important reservoir for bacteria. Also, resident bacteria tend to persistently remain into adenoids by producing biofilm [52]. So, they can become resistant to defensive mechanisms and antibiotics. Moreover, adenoiditis is clinically relevant as it may spread to other organs, worsening otitis, rhinosinusitis, and lower airways infections [53]. Therefore, adenoiditis represents a relevant burden in children, mainly when recurrent. Preventing recurrent adenoiditis, often associated with $\mathrm{AH}$, represents a compelling challenge in clinical practice. Acute adenoiditis is defined by signs and symptoms of acute infection, including nasal obstruction, posterior mucopurulent discharge, oral breathing, dry mouth, closed posterior 
rhinolalia, halitosis, and fever. Recurrent adenoiditis associated with AH causes sleep disorders, impaired craniofacial growth, reduced attention, and also enuresis. Consequently, recurrent adenoiditis is a common reason for antibiotic prescription in the paediatric age. A preventive strategy could be therefore very fruitful. In this regard, an interesting option has been highlighted by the study of the microbiome [54, 55]. On the other hand, the physiological rhino-pharyngeal microbiome does constitutively inhibit the growth of local pathogens. It has been demonstrated that the administration of "good" bacteria (the so-called "Bacteriotherapy") could exert preventive effects on infections. In this regard, Bacteriotherapy was successfully administered as a nasal spray for preventing recurrent acute otitis media $[56,57]$.

\section{Rhinosinusitis}

Sinusitis usually refers to inflammation of the nasal sinuses. However, as it is very commonly associated with the inflammation of the nasal mucosae, such as rhinitis, the term rhinosinusitis (RS) has been considered more correct [58]. In clinical practice, acute RS (ARS) is diagnosed in the presence of nasal symptoms, including nasal congestion and rhinorrhea, persisting for more than 7-10 days without any improvement [59,60]. RS differs from the common cold because this is usually self-limiting and usually resolves by $7-10$ days [60-62]. The symptoms of ARS tend to resolve within 3-4 weeks; however, if sinus inflammation persists (regardless of the medical management), it is evolving to chronic RS (CRS), defined by a duration longer than 8-12 weeks [63]. Therefore, the diagnosis of RS often relies on the clinical ground, including the duration of nasal symptoms, the characteristics of nasal discharge (purulent), and other symptoms, such as facial pain and fever. However, fibre-optic endoscopy is the gold standard diagnostic tool and its use is mandatory in clinical practice [64]. Computerized tomography (CT) may be required whenever the suspicion of extra-sinus complications should arise $[65,66]$. Moreover, CT is useful to detect nasal polyps in CRS patients. According to the endoscopic and/or radiological findings, there are two main CRS phenotypes: CRS with nasal polyposis (CRSwNP) and CRS without nasal polyposis (CRSsNP).

\section{Common cold}

The common cold is surely the most common infective disease at any age. Viruses are the main cause of the common cold, mainly concerning rhinovirus. Usually, the diagnosis is clinically-grounded. It is a self-limiting infection but could worsen and cause acute rhinosinusitis, mainly in presence of local predisposing factors, including adenoid hypertrophy, nasal polyposis, septal deviation, promoting mechanical obstruction or systemic factors, including allergy, ciliary dyskinesia, and immune deficiency. Acute rhinosinusitis could be suspected when an episode of common cold lasts for more than 10 days or symptoms worsen after 5 years [67]. Specific treatments of the common cold do not exist as well as vaccination is ineffective. Therefore, symptomatic treatment is usually prescribed in common practice. However, early treatment addressed to remove secretions and dampen microbial load could be desirable.

\section{Recurrent rhinosinusitis}

Recurrent rhinosinusitis (RRS) is defined by multiple episodes of acute rhinosinusitis (ARS), mainly of bacterial aetiology [51]. As defined by International guidelines $[63,68]$, the diagnosis of ARS is based on the clinical history and endoscopic assessment. As punctually pointed out by the guidelines, treatment includes topical anti-inflammatory drugs and antibiotics use based on clinical ground. On the other hand, anti-inflammatory agents may have relevant side effects, mainly in children. Also, antibiotic overuse is frequently associated with outgrowth of multi-resistant microbes as above mentioned. An effective RRS prevention might significantly affect the risk of complications, medical costs, and social and family impact. On the other hand, many past attempts of prevention were usually expensive, longlasting, and seldom fruitless or accompanied by adverse events. Therefore, preventing RRS using an alternative way might represent an interesting and stimulating issue as recently reported [69]. RRS prevention may include bacteriotherapy, probiotic administration, vitamins, oligo-elements, or the use of immune-stimulant compounds [70].

\section{Allergic rhinitis}

Allergic rhinitis (AR) is the most common immunemediated disorder as it may affect up to $40 \%$ of the paediatric population [71]. AR has clinical relevance as is frequently associated with comorbidities, including other allergies, asthma, rhinosinusitis, recurrent respiratory infections, otitis, adenoid hypertrophy $(\mathrm{AH})$ and tonsillar hypertrophy $(\mathrm{TH})$, as recently reported by several recent studies [72-75]. Moreover, the possible correlation between AR and AH-TH has been investigated by some studies which reported a positive association between the two disorders [76-80]. Atopy, such as the genetic predisposition to allergic diseases, is also common in AR children.

It is well known that the rhinologist visits children complaining of nasal symptoms daily. A pale mucosa in the nasal cavity has been traditionally considered a sign suggesting allergic rhinitis by most ORL specialists [81, 82]. However, it has been evidenced that turbinate hypertrophy is a sign with higher predictive reliability to suspect 
allergic rhinitis during an ORL visit both in children and adults [83, 84]. Nasal obstruction is, in fact, a common symptom of allergic rhinitis as it has been reported that it is present in about $80 \%$ of children with allergic rhinitis [85]. Consistently, it has been reported that also bronchial airflow limitation, documented by simple spirometry, may be able to suspect the presence of sensitization, such as positive skin prick test $[86,87]$. Furthermore, it has to be highlighted that to define a diagnostic marker there is the need to fulfil a series of pragmatic requirements as recently pointed out [88].

$A R$ is characterized by typical nasal symptoms and IgE-mediated inflammation [89]. A type 2 inflammation is initiated by causal allergen exposure [90]. Mediators and cytokines are actors involved in the scenario of inflammatory events. A typical pattern of inflammatory cells infiltrates the nasal mucosa: it includes eosinophils, neutrophils, and mast cells. A clear-cut association between allergen exposure and nasal inflammation has been documented exhaustively using these criteria in the past [91-93]. AR treatment is based on antihistamines and intranasal corticosteroids administration [94]. These medications are usually effective and safe but exert symptomatic activity that shortly disappears after discontinuation. The only cure for AR is allergen-specific immunotherapy that consists of the administration of the causal allergen for a long period [94]. Ancillary treatments may include nasal irrigation, non-steroidal antiinflammatory compounds, and preventive therapies as discussed later.

\section{Non-allergic rhinitis (NAR)}

Non-allergic rhinitis is an umbrella definition that includes different phenotypes and endotypes. The most common types of non-allergic rhinitis are inflammatory rhinitis and vasomotor rhinitis [95]. Inflammatory rhinitis is characterized by nasal symptoms sustained by a non-specific hyperreactivity and nasal non-IgE mediated inflammation. The diagnosis is based on clinical history, negative allergic tests, and the detection of inflammatory cells infiltrating the nose. Different types of NAR have been identified and classified considering the predominant inflammatory cells: nonallergic rhinitis with eosinophils (NARES), non-allergic rhinitis with mast cells (NARMA), non-allergic rhinitis with eosinophils and mast cells (NARESMA), non-allergic rhinitis with neutrophils (NARNE).

The treatment of non-allergic inflammatory rhinitis is merely symptomatic, using topical or oral antihistamines, topical anticholinergic drugs, and intranasal corticosteroids. Nasal lavage may alleviate symptoms.

Vasomotor rhinitis is caused by nasal hyperreactivity mainly due to exaggerated neural reflex. The treatment may be advantaged also by topical anticholinergic agents [95].

\section{Pragmatic work-up}

In clinical practice, AR diagnosis is based on the consistency between clinical history and the assessment of allergen-specific IgE [94]. Nasal allergic inflammation may be documented by nasal cytology as previously proposed [96], even though the main criticism is the lack of standardized criteria. In this regard, a series of statistical criteria should be required to standardize a test [88]. Very recently, a standardization of nasal cytology has been reported [97].

On the other hand, some studies investigated nasal inflammation using flow cytometry, even though most of them aimed at evaluating issues far from conventional rhinology [98-104]. Flow cytometry allows defining a series of additional aspects in comparison with traditional nasal cytology, including the cellular volume and density, the antigenic and genetic cellular pattern, and the functional state, such as activation. Moreover, flow cytometry is automated and well standardized, so it may be considered as a precise and accurate method to analyze the cellular pattern in nasal inflammation. In this regard, it has been recently reported that flow cytometry is an adjunctive and reliable tool in the work-up of AR [105]. Also, nasal cytology, including flow cytometry, is fundamental to diagnose inflammatory non-allergic rhinitis as it is the unique test able to identify and count inflammatory cells in patients with non-allergic rhinitis [106].

Another useful clinical parameter, that is very simple and easy, is the visual analogue scale (VAS). VAS is a psychometric test able to assess the perception of symptoms and is commonly used in clinical practice. VAS also well correlates with objective measurement of nasal obstruction and can be re-assessed to evaluate change over time [107, 108].

However, it has to be underlined that nasal fibreoptic endoscopy is the gold standard diagnostic tool in the management of all UA disorders. At present, endoscopy is a mandatory and unavoidable step in the ORL workup as it gives unique information about the anatomy and morphology of UA [109].

\section{Therapeutic strategies for UA diseases based on local and real-world studies}

The burden and cost of inflammatory, infectious, and allergic disorders involving UA are increasing worldwide. Thus, strategies need to change management to support the transformation of the healthcare system for integrated care as recently proposed [110]. In this regard, integrated care pathways are structured multidisciplinary care plans that detail the key step of patient care [111]. They promote the application of guideline recommendations to clinical practice $[112,113]$. Therefore, a multidisciplinary approach should include both diagnostic procedures and therapeutic strategies. 
There is evidence that several therapeutic options may be effective in the treatment of UA diseases, as demonstrated by several studies that investigated the effectiveness and safety of different medication classes. In this regard, a synthetic review of a series of studies exploring the innovative use of conventional medications or the clinical application of complementary medicine is presented. As considered in the introduction, we selected studies conducted in Italy and real-world setting as they could realistically reflect what happens daily in clinical practice. Moreover, most of them were performed following a randomized and controlled design.

Nasal irrigation with hypertonic saline significantly reduced the adenoid size in children with adenoid hypertrophy [114]. Salso-sulfide thermal water was successfully used in children with RRI [115]. Consistently, salsobromo-iodine thermal water reduced postnasal driprelated cough in children suffering from acute upper airway infection [116]. Antibiotics, such as tobramycin and thiamphenicol, were intranasally administered using a nasal micronized douche in children with acute rhinopharyngitis: both treatments significantly reduced the symptom severity $[117,118]$. An original therapeutic strategy was adopted in children with perennial allergic rhinitis, i.e. a continuous schedule; long-term cetirizine administration significantly improved symptoms and reduced the use of symptomatic drugs in comparison with on-demand cetirizine [119]. Another study demonstrated that fexofenadine, a second-generation antihistamine, was able to significantly reduce nasal congestion in patients with perennial allergic rhinitis [120]. Corticosteroids, the most potent anti-inflammatory drug, may also reduce adenoid volume if administered topically in children with adenoid hypertrophy, as reported for intranasal flunisolide [121]. Notably, it was also demonstrated that nasal flunisolide application could also reduce the adenoid surgery [122]. Also, intranasal flunisolide, a topical corticosteroid, significantly affected nasal symptoms in patients with non-allergic rhinitis [123]. Flunisolide is also indicated in chronic rhinosinusitis as it is effective and has an optimal quality/cost ratio [124]. However, the nasal device and the excipients are relevant factors for improving the prolonged efficacy, safety, preference, and compliance as demonstrated for mometasone furoate nasal spray [125]. In particular, mometasone has a favourable safety profile also in paediatric patients as recently reported [126].

Considering complementary medicine, there is growing evidence demonstrating its useful role in the management of upper airway diseases. In this regard, hyaluronic acid exerts important anti-inflammatory activity associated with immune-modulatory and lubricant effects in children with bacterial acute rhinopharyngitis [127], in patients with allergic, non-allergic, and mixed rhinitis [128], and patients after functional endoscopic sinus surgery [129].
Resveratrol, a phenol characterized by anti-viral activity and anti-inflammatory activity, may significantly reduce nasal symptoms in children with pollen-induced allergic rhinitis [130]. Also, resveratrol plus carboxymethyl- $\beta$ glucan reduced the number of respiratory infections in children with allergic rhinitis [131]. This result was consistent with a similar study conducted in children with RRI [132]. An empiric approach in children with secondary sinonasal headache, consisting of nasal aerosol containing pirometaxine and copper sulfate associated with pidolate magnesium and exclusion diet, significantly improved symptom severity [133]. Cucurbitacins extract, as glycosylates triterpenes, resolved otitis media with effusion in $93.3 \%$ of treated children [134]. An oral nutraceutical, containing quercetin, extract of Perilla, and vitamin D3, was investigated in a randomized controlled study conducted in children with allergic rhinitis. The results provided evidence that this multicomponent nutraceutical significantly reduced the occurrence of clinical worsening and prevent rhinitis exacerbations in comparison with placebo $[135,136]$. Probiotics are widely self-administered by the patients, but scientific evidence is scarce. Lactobacillus reuteri has been employed in asthmatic children: it significantly reduced bronchial inflammation and respiratory symptoms [137]. Moreover, probiotics may reduce the occurrence of infectious rhinitis which is commonly associated with allergic rhinitis [138]. If associated with vitamin D3, L reuteri provided more interesting outcomes [139]. Finally, as above discussed, bacteriotherapy, such as the administration of "good" bacteria (usually saprophytic), may be a promising approach in preventing respiratory infections as demonstrated in children with recurrent acute otitis media [140]. A preliminary study showed that bacteriotherapy could also prevent adenoid surgery [141]. More recently, it has been reported that also oral bacteriotherapy may significantly reduce the number of streptococcal infections, the use of antibiotics, and the scholar absences in children with recurrent streptococcal pharyngotonsillitis caused by Group A $\beta$-haemolytic Streptococcus [142].

Enoxolone, a potent anti-inflammatory, and immunomodulatory molecule, associated with mannitol, an osmotic anti-oedema agent, have been demonstrated able to improve the nasal mucociliary transport time [143], to reduce nasal eosinophilia in allergic children [144], and significantly reduce the severity of nasal congestion $[145,146]$.

\section{Future perspectives}

There is a growing body of literature about a new promising approach to treat upper airway disorders using biologics [147]. Many trials have been conducted using biologics, such as omalizumab, a monoclonal antibody targeted toward IgE, mepolizumab, an anti-IL-5 agent, duplizumab, and anti-IL-4 and IL-3 biologic, to treat 
upper airway disorders, including allergic rhinitis and chronic rhinosinusitis with nasal polyps [148-150]. The outcomes were meaningful, however, it should be noted that the indication in upper airway diseases is still off-label.

\section{Conclusion}

Upper airways should be adequately investigated performing an appropriate workup, including fibreoptic endoscopy and cytology. Inflammatory UA diseases should be treated with effective and safe medications. Respiratory infections deserve adequate observation, antibiotics should be prescribed with careful attention, and preventive strategy should be preferred. Allergic disorders can be successfully treated with specific therapy and allergic symptoms can be optimally relieved with medications. However, inflammation, infection, and allergy frequently coexist, therefore an integrated multidisciplinary approach should be considered in clinical practice. Also, conventional treatment may be opportunely associated and integrated using complementary medicine.

\section{Acknowledgements}

Not applicable.

\section{Authors' contributions}

This study was a collaboration between all authors. Author GC searched the literature and wrote the manuscript. ILM, FB, and AV reviewed and discussed the manuscript. All authors read and approved the final manuscript.

\section{Funding}

The publication has been supported by the Associazione Italiana Vie Aeree Superiori.

\section{Availability of data and materials}

Not applicable.

\section{Ethics approval and consent to participate}

Not applicable.

\section{Consent for publication}

Not applicable.

\section{Competing interests}

The authors declare that they have no competing interests.

\section{Author details}

'UOSD Video-Endoscopia delle VAS, P.O. San Gennaro - ASL Napoli 1-centro, Naples, Italy. ${ }^{2}$ ENT Department, University of Catania, Catania, Italy. ${ }^{3}$ Primary Care Paediatrics, ASL Caserta, Caserta, Italy. ${ }^{4}$ Allergy Clinic, Casa di Cura Villa Montallegro, Via Boselli 5, 16146 Genoa, Italy.

Received: 6 October 2019 Accepted: 29 January 2020

Published online: 10 February 2020

\section{References}

1. Pitt E, Gallegos D, Comans T, Cameron C, Thornton L. Exploring the influence of local food environments on food behaviours: a systematic review of qualitative literature. Public Health Nutr. 2017;20:2393-405.

2. Brennan A, Akehurst R. Modelling in health economic evaluation. What is its place? What is its value? Pharmacoeconomics. 2000;17:445-59.

3. Use of real-world evidence to support regulatory decision-making for medical devices. Guidance for industry and Food and Drug Administration staff document issued on August 31, 2017. Bethesda: US Food and Drug Administration, US Department of Health and Human Services Food and
Drug Administration, Center for Devices and Radiological Health Center for Biologics Evaluation and Research; 2017.

4. Sherman RE, Anderson SA, Dal Pan GJ, Gray GW, Gross T, Hunter NL, et al. Real-world evidence-what is it and what can it tell us? N Engl J Med. 2016;375:2293-7.

5. Ciprandi G, Cirillo I. The lower airway pathology of rhinitis. J Allergy Clin Immunol. 2006;118:1105-9.

6. Ciprandi G, Caimmi D, Miraglia del Giudice M, La Rosa M, Salpietro C, Marseglia G, et al. Recent developments in united airways disease. Allergy Asthma Immunol Res. 2012:4:171-7.

7. Fahey T, Stocks M, Thomas T. Systematic review of the treatment of upper respiratory tract infection. Arch Dis Child. 1998;79:225-30.

8. Wald ER, Guerra N, Byers C. Upper respiratory tract infections in young children: duration and frequency of complications. Pediatrics. 1991;87:129.

9. Wigand ME. Endonasal sinus surgery with endoscopical control: from radical operation to rehabilitation of the mucosa. Endoscopy. 1978;10:255-60.

10. Dykewicz MS. Rhinitis and sinusitis. J Allergy Clin Immunol. 2003;111:S520-9.

11. Watkins DS, Lewis RH, Bascalin KA, et al. Expression and localization of the inducible isoform of nitric oxide synthase in nasal epithelium. Clin Exp Allergy. 1998;28:211-9.

12. Djiupesland $P G$, Chatkin $J M$, Qian $W$, et al. Nitric oxide in nasal airway: a new dimension in otorhinolaryngology. Am J Otolaryngol. 2001;22:19-32.

13. Brandzaeg P. Immunobarriers of the mucosa of the upper respiratory and digestive pathways. Acta Otolaryngol (Stockh). 1988;105:172-80.

14. Stankiewicz J. Chronic sinusitis. In: Johnson JT, Yu VL, editors. Infectious diseases and antimicrobial therapy of the ears, nose and throat. Philadelphia: WB Saunders Co; 1997.

15. Ciprandi G, Buscaglia S, Pesce G. Minimal persistent inflammation is present at mucosal level in patients with asymptomatic rhinitis and mite allergy. J Allergy Clin Immunol. 1995;96:971-9.

16. Wolcott RD, Ehrlich GD. Biofilms and Chronic Infections. JAMA. 2008;299: 2682-4.

17. Zuliani G, Carron M, Gurrola J, Coleman C, Haupert M, Berk R, et al. Identification of adenoid biofilms in chronic rhinosinusitis. Int J Pediatr Otorhinolaryngol. 2006;70:1613-7.

18. Ivarsson M, Ebenfelt A, Lundberg C. Do the leukocytes in the surface secretion on the adenoid have an immunological function? Acta Otolaryngol (Stockh). 1997;117:872-8.

19. de Martino M, Vierucci A, Appendino C. Children with recurrent respiratory infections. Immunol Ped. 1981;4:76-81.

20. de Martino M, Ballotti S. The child with recurrent respiratory infections: normal or not? Ped Allergy Immunol. 2007;18(Suppl. 18):13-8.

21. Paradise JL, Bluestone CD, Colborn DK, Bernard BS, Rockette HE, Kurs-Lasky $\mathrm{M}$. Tonsillectomy and adenotonsillectomy for recurrent throat infection in moderately affected children. Pediatrics. 2002;1 10:7-15.

22. Greenberg D, Bilenko N, Liss Z. The burden of acute otitis media on the patient and family. Eur J Pediatr. 2003;162:576-81.

23. de Benedictis FM, Bush A. Recurrent lower respiratory tract infections in children. BMJ. 2018;362:k2698.

24. Karevold G, Kvestad E, Nafstad P, Kvaerner KJ. Respiratory infections in schoolchildren: co-morbidity and risk factors. Arch Dis Child. 2006;91:391-5.

25. Thompson M, Vodicka TA, Blair PS, Buckley DI, Heneghan C, Hay ADTARGET Programme Team. Duration of symptoms of respiratory tract infections in children: systematic review. BMJ. 2013;347:f7027.

26. Toivonen L, Karppinen S, Schuez-Havupalo L, Teros-Jaakkola T, Vuononvirta $J$, et al. Burden of recurrent respiratory tract infections in children: A prospective cohort study. Pediatr Infect Dis J. 2016;35:e362-9.

27. Patria MF, Esposito $S$. Recurrent lower respiratory tract infections in children: a practical approach to diagnosis. Paediatric Respir Rev. 2013;14:53-60.

28. Fahy JV. Type 2 inflammation in asthma - present in most, absent in many. Nat Rev Immunol. 2015;15:57-65.

29. Ciprandi G, Tosca MA, Silvestri M, Ricciardolo FLM. Inflammatory biomarkers for asthma endotyping and personalized therapy. Exp Rev Clin Immunol. 2017;13:715-21.

30. Ciprandi G, Tosca MA, Fasce L. Allergic children have more numerous and severe respiratory infections than non-allergic children. Ped Allergy Immunol. 2006;17:389-91.

31. Cirillo I, Marseglia G, Klersy C, Ciprandi G. Allergic patients have more numerous and prolonged respiratory infections than nonallergic subjects. Allergy. 2007;62:1087-90. 
32. Ciprandi G, Sormani MP, Cirillo I, et al. Upper respiratory infections and SLIT: preliminary evidence. Ann Allergy. 2009;102:262-3.

33. Griffin MR, Walker FJ, Iwane MK, et al. New vaccine surveillance network study group: epidemiology of respiratory infections in young children: insights from the new vaccine surveillance network. Pediatr Infect Dis J. 2004:23:188-92.

34. Li J, Song X, Yang T, et al. A Systematic Review of Antibiotic Prescription Associated with Upper Respiratory Tract Infections in China. Medicine (Baltimore). 2016;95:e3587

35. Alexandrino AS, Santos R, Melo C, et al. Caregivers' education vs rhinopharyngeal clearance in children with upper respiratory infections: impact on children's health outcomes. Eur J Pediatr. 2017;176:1375-83.

36. Regli A, Becke K, von Ungern-Sternberg BS. An update on the perioperative management of children with upper respiratory tract infections. Curr Opin Anaesthesiol. 2017;30:362-7.

37. Nazzari E, Torretta S, Pignataro L, et al. Role of biofilm in children with recurrent upper respiratory tract infections. Eur J Clin Microbiol Infect Dis. 2015;34:421-9.

38. Gisselson-Solen M. Acute otitis media in children - current treatment and prevention. Curr Infect Dis Rep. 2015;17:22.

39. Marchisio P, Bellussi L, Di Mauro G, Doria M, Felisati G, Longhi R, et al. Acute otitis media: from diagnosis to prevention. Summary of the Italian guideline. Int J Ped Otorhinolaryng. 2010;74:1209-16.

40. Heidemann CH, Lous J, Berg J, Christensen JJ, Hakonsen SJ, Jakobsen M, et al. Danish guidelines on management of otitis media in preschool children. Int J Ped Otorhinolaryng. 2016;87:154-63.

41. Lieberthal AS, Carroll AE, Chonmaitree T, Ganiats TG, Hoberman A, Jackson MA, et al. The diagnosis and management of acute otitis media. Pediatrics. 2013;131:e964-99.

42. Siddiq S, Grainger J. The diagnosis and management of acute otitis media: American Academy of Pediatrics guidelines 2013. Arch Dis Child Educ Pract. 2015;100:193-7.

43. Kitamura K, lino Y, Kamide Y, Kudo F, Nakayama T, Suzuki K, et al. Clinical practice guidelines for the diagnosis and management of acute otitis media (AOM) in children in Japan-2013 update. Auris Nasus Larynx. 2015;42:99-106.

44. Rettig E, Tunkel DE. Contemporary concepts in management of acute otitis media in children. Otolaryngol North Am. 2014;47:651-72.

45. Tamir SO, Shemesh S, Oron Y, Marom T. Acute otitis media guidelines in selected developed and developing countries: uniformity and diversity. Arch Dis Child. 2016:0:1-8.

46. Morris PS, Leach AJ. Antibiotics for persistent nasal discharge (rhinosinusitis) in children. Cochrane Database Syst Rev. 2008:2:CD001094.

47. Molstad S, Erntell M, Hanberger I, Melander E, Norman C, Skoog G, et al. Sustained reduction of antibiotic use and low bacterial resistance: 10-year follow-up of the Swedish Strama programme. Lancet Infect Dis. 2008;8:125-32.

48. Barbieri E, Donà D, Cantarutti A, Lundin R, Scamarcia A, Corrao G, et al. Antibiotic prescriptions in acute otitis media and pharyngitis in Italian pediatric outpatients. It J Pediatrics. 2019;45:103.

49. Marseglia GL, Caimmi D, Pagella F, et al. Adenoids during childhood: the facts. Int J Immunopathol Pharmacol. 2011;24(4 Suppl):1-5.

50. Marseglia G, Poddighe D, Caimmi D, Marseglia A, Caimmi S, Ciprandi G, et al. Role of adenoids and adenoiditis in children with allergy and otitis media. Curr Allergy Asthma Rep. 2009;9:460-4.

51. Mansback Al, Brihave P, Casimir G, et al. Clinical aspects of chronic ENT inflammation in children. B ENT. 2012;8(Suppl 19):83-101.

52. Casselbrant ML. What is wrong in chronic adenoiditis/tonsillitis: anatomical considerations. Int J Pediatr Otorhinolaryngol. 1999;49(Suppl 1):S133-5.

53. Cj P, Hiller LN, Nistico L, et al. The role of biofilms in otolaryngologic infections. Curr Opin Otolaryngol Head Neck Surg. 2007;15:347-51.

54. Graham JM, Scadding GK, Bull PD. Pediatric ENT. Berlin-Heidelberg: Springer; 2008.

55. Maron T, Marchisio P, Tamir SO, Torretta S, Gavriel H, Esposito S. Complementary and alternative medicine treatment options for otitis media. Medicine. 2016;95:e2695.

56. Gao Z, Kang Y, Yu J, Ren L. Human pharyngeal microbiome may play a protective role in respiratory tract infections. Genomics Proteomics Bioinformatics. 2014;12:144-50.

57. Marchisio P, Santagati M, La Mantia I, Scillato M. Streptococcus salivarius 24SMB administered by nasal spray for the prevention of acute media otitis in otitis-prone children. Eur J Microbiol Infect Dis. 2015:34:2377-83.

58. Tan R, Spector S. Pediatric sinusitis. Curr Allergy Asthma Rep. 2007;7:21-426.
59. Magit A. Pediatric rhinosinusitis. Otolaryngol Clin. 2014;47:733-46.

60. Wald ER, Applegate KE, Bordley C, American Academy of Pediatrics. Clinical practice guidelines for the diagnosis and management of acute bacterial sinusitis in children aged 1 to 18 years. Pediatrics. 2013;132:e262-80.

61. Cyr C, Racette R, Leduc C, Blais C. Do symptoms and initial clinical probability predict the radiological diagnosis of acute sinusitis in children? Paediatr Child Health. 2001;6:536-9.

62. Ueda D, Yoto $Y$. The ten-day mark as a practical diagnostic approach for acute paranasal sinusitis in children. Pediatr Infect Dis J. 1996;15:576-9.

63. Fokkens WJ, Lund VJ, Mullol J, et al. European position paper on Rhinosinusitis and nasal polyps 2012. Rhinol Suppl. 2012:23:1-298.

64. Rimmer J, Hellings P, Lund VJ, Alobid I, Beale T, Dassi C, et al. European position paper on diagnostic tools in rhinology. Rhinology. 2019;57(Suppl S28):1-41.

65. Bhattacharyya N, Jones DT, Hill M, Shapiro NL. The diagnostic accuracy of computed tomography in pediatric chronic rhinosinusitis. Arch Otolaryngol Head Neck Surg. 2004;130:1029-32.

66. Ramadan HH. Pediatric sinusitis: update. J Otolaryngol. 2005;34:S14-7.

67. Peters AT, Spector S, Hsu J, et al. Joint task force on practice parameters, representing the American Academy of allergy, asthma and immunology, the American college of allergy, asthma and immunology, and the joint council of allergy, asthma and immunology. Diagnosis and management of rhinosinusitis: a practice parameter update. Ann Allergy Asthma Immunol. 2014;113:347-85.

68. Orlandi RR, Kingdom T, Hwang PH, et al. International consensus statement on allergy and rhinology: Rhinosinusitis. Int Forum Allergy Rhinol. 2016:6(Suppl 1):S22-209.

69. Tarantino V, Savaia V, D’Agostino R, Silvestri M, Passali FM, Ciprandi G. Bacteriotherapy in children with recurrent upper respiratory tract infections. Eur Rev Med Pharmacol Sci. 2019;23:39-43.

70. Ciprandi G, Aragona SE, Drago L, La Mantia I. The nutraceuticals: a new therapeutic strategy in the management of digestive and respiratory disorders. Acta Biomed. 2019;7-S:5-7.

71. Kakli HA, Riley TD. Allergic rhinitis. Prim Care. 2016:43:465-75.

72. Hoyte FCL, Nelson HS. Recent advances in allergic rhinitis. F1000Res. 2018;23:7.

73. Blaiss MS, Hammerby E, Robinson S, Kennedy-Martin T, Buchs S. The burden of allergic rhinitis and allergic rhinoconjunctivitis on adolescents: A literature review. Ann Allergy Asthma Immunol. 2018:121:43-52.e3.

74. Ellis AK, Tenn MW. Advances in rhinitis: Models and mechanisms. Ann Allergy Asthma Immunol. 2018;121:61-4.

75. Okubo K, Kurono Y, Ichimura K, Enomoto T, Okamoto Y, Kawauchi H, et al. Japanese guidelines for allergic rhinitis 2017. Allergol Int. 2017;66:205-19.

76. Johnston J, McLaren H, Mahadevan M, Douglas RG. Clinical characteristics of obstructive sleep apnea versus infectious adenotonsillar hyperplasia in children. Int J Pediatr Otorhinolaryngol. 2019;116:177-80.

77. Ekici NY, Görgülü O, Yucel G, Külahcı Ö, Arıkan OK, Durmaz C. Can the number of eosinophils in adenoid and tonsil tissue determine the allergy in children? Int J Pediatr Otorhinolaryngol. 2018;108:35-9.

78. Cho KS, Kim SH, Hong SL, Lee J, Mun SJ, Roh YE, Kim YM, Kim HY. Local Atopy in Childhood Adenotonsillar Hypertrophy. Am J Rhinol Allergy. 2018; 32:160-6.

79. Sih T, Mion O. Allergic rhinitis in the child and associated comorbidities. Pediatr Allergy Immunol. 2010:21:e107-13.

80. Ameli F, Brocchetti F, Tosca MA, Signori A, Ciprandi G. Adenoidal hypertrophy and allergic rhinitis: is there an inverse relationship? Am J Rhinol Allergy. 2013;27:e5-10.

81. Caplin I, Haynes JT, Houser D. Significance of the pale, boggy nasal mucosa. J Indiana State Med Assoc. 1968;61:981-2.

82. Motomura C, Odajima H, Yamada A, Taba N, Murakami Y, Nishima S. Pale nasal mucosa affects airflow limitations in upper and lower airways in asthmatic children. Asia Pac Allergy. 2016;6:220-5.

83. Ameli F, Brocchetti F, Tosca MA, Signori A, Ciprandi G. Nasal endoscopy in children with suspected allergic rhinitis. Laryngoscope. 2011;121:2055-9.

84. Hamizan AW, Christensen JM, Ebenzer J, et al. Middle turbinate oedema as a diagnostic marker of inhalant allergy. Int Forum Allergy Rhinol. 2017;7:37-42.

85. La Mantia I, Andaloro C. Demographic and clinical features predictive of allergic versus non-allergic rhinitis in children aged 6-18 years: a singleCentre experience of 1535 patients. Int J Ped Otorhinolaryngol. 2017:98: 103-9.

86. Cirillo I, Gallo F, Ciprandi G. Could routine spirometry suggest sensitization in the military medicine setting? J R Army Med Corps. 2018;164:58-60. 
87. Cirillo I, Gallo F, Ciprandi G. Impaired spirometry may predict bronchial hyper-responsiveness. J Allergy Clin Immunol Pract. 2018;6:2127-9.

88. Ciprandi G, Silvestri M, Pistorio A. Defining a diagnostic marker: a pragmatic requirement. Int Forum Allergy Rhinol. 2017;7:632-3.

89. Wise SK, Lin SY, Toskala E, et al. International Consensus Statement on Allergy and Rhinology: Allergic Rhinitis. Int Forum Allergy Rhinol. 2018;8:200.

90. Annunziato F, Romagnani C, Romagnani S. The 3 major types of innate and adaptive cell-mediated effector immunity. J Allergy Clin Immunol. 2015;135: 626-35

91. Ciprandi G, Pronzato C, Ricca V, Bagnasco M, Canonica GW. Evidence of intercellular adhesion molecule-1 expression on nasal epithelial cells in acute rhinoconjunctivitis caused by pollen exposure. J Allergy Clin Immunol. 1994:94:738-46.

92. Ciprandi G, Pronzato C, Ricca V, Passadaqua G, Bagnasco M, Canonica GW. Allergen-specific challenge induces intracellular adhesion molecule-1 (ICAM1 or CD54) on nasal epithelial cells in allergic subjects. Am J Respir Crit Care Med. 1994;150:1653-9.

93. Ricca V, Landi M, Ferrero P, Bairo A, Tazzer C, Ciprandi G. Minimal persistent inflammation is present also in patients with seasonal allergic rhinitis. J Allergy Clin Immunol. 2000;105:54-7.

94. Brożek JL, Bousquet J, Agache I, et al. Allergic Rhinitis and its Impact on Asthma (ARIA) guidelines-2016 revision. J Allergy Clin Immunol. 2017;140: 950-8.

95. Ciprandi G. Treatment of nonallergic perennial rhinitis. Allergy. 2004;56(S76): $16-23$.

96. Meltzer EO, Jalowayski AA. Nasal cytology in clinical practice. Am J Rhinol. 1988;2:47-54

97. Ciprandi G, Silvestri M. Standardization of the nasal cytology in the work-up of allergic rhinitis. Ann All Asthma Immunol 2019 (in press).

98. Horvath KM, Herbst M, Zhou H, Zhang H, Noah TL, Jaspers I. Nasal lavage natural killer cell function is suppressed in smokers after live attenuated influenza virus. Respir Res. 2011;12:102.

99. Beiersdorf N, Schien M, Hentschel J, Pfister W, Markert UR, Mainz JG. Soluble inflammation markers in nasal lavage from CF patients and healthy controls. J Cyst Fibros. 2013;12(3):249-57.

100. Aurora R, Chatterjee D, Hentzleman J, Prasad G, Sindwani R, Sanford T. Contrasting the microbiomes from healthy volunteers and patients with chronic rhinosinusitis. JAMA Otolaryngol Head Neck Surg. 2013;139:1328-38.

101. Oshansky CM, Gartland AJ, Wong SS, Jeevan T, Wang D, Roddam PL, et al. Mucosal immune responses predict clinical outcomes during influenza infection independently of age and viral load. Am J Respir Crit Care Med. 2014;189:449-62.

102. Meng Q, Liu X, Li P, He L, Xie J, Gao X, et al. The influence of house dust mite sublingual immunotherapy on the TSLP-OX40L signalling pathway in patients with allergic rhinitis. Int Forum Allergy Rhinol. 2016;6:862-70.

103. Lee KS, Yu J, Shim D, Choi H, Jang MY, Kim KR, et al. Local immune responses in children and adults with allergic and nonallergic rhinitis. PLoS One. 2016;11:e0156979.

104. Takahashi T, Kato A, Berdnikovs S, Stevens WW, Suh LA, Norton JE, et al. Microparticles in nasal lavage fluids in chronic rhinosinusitis: potential biomarkers for diagnosis of aspirin-exacerbated respiratory disease. J Allergy Clin Immunol. 2017;140:720-9.

105. Varricchio A, Tajana G, Tommasino C, Melillo E, Camerlingo S, Rosolino I, et al. Feasibility of the flow cytometry in the rhinologist's clinic. Acta Otorhinolaryngol Ital. 2019. https://doi.org/10.14639/0392-100X-2216. Epub ahead of print.

106. Gelardi M, Fiorella ML, Russo C, Fiorella R, Ciprandi G. Role of nasal cytology. Int J Immunopathol Pharm. 2010;23:45-9.

107. Ciprandi G, Mora F, Cassano M, Gallina AM, Mora R. V.A.S. and nasal obstruction in persistent allergic rhinitis. Otolaryngol HNS. 2009;141:527-9.

108. Ciprandi G, Tosca MA, Silvestri M. Measuring the perception of symptoms, drug use, and allergen immunotherapy efficacy using the visual analogue scale. Exp Review Clin Immunol. 2014;10:179-82.

109. Karabulut B, Sahin-Onder S, Erkmen B, Cetemen A, Gergin O. Predictive fiberoptic endoscopic findings of the upper airway in children with allergic rhinitis. Int J Ped Otorhinolaryngol. 2019;124:143-6.

110. Bousquet J, Pfaar O, Togias A, Schunemann HJ, Ansotegui I, Papadopoulos NG, et al. 2019 ARIA Care pathways for allergen immunotherapy. Allery. 2019;74(11):2087-102.

111. Campbell H, Hotchkiss R, Bradshaw N, Porteous M. Integrated care pathways. BMJ. 1998;316(7125):133-7.
112. Hujala A, Taskinen H, Rissanen S, Richardson E, van Ginneken E. How to support integration to promote care for people with multimorbidity in Europe? European observatory policy briefs. Copenhagen: European Observatory on Health Systems and Policies; 2017.

113. Palmer K, Marengoni A, Forjaz MJ, et al. Multimorbidity care model: recommendations from the consensus meeting of the joint action on chronic diseases and promoting healthy ageing across the life cycle (JACHRODIS). Health Policy. 2018;122(1):4-11.

114. Ciprandi G, Varricchio A, Capasso M, Varricchio AM, De Lucia A, Ascione E, et al. Hypertonic saline solution in children with adenoidal hypertrophy: preliminary evidence. Eur J Inflamm. 2007:5:159-63.

115. Varricchio A, Giuliano M, Capasso M, Del Gaizo D, Ascione E, De Lucia A, et al. Salso-sulphide thermal water in the prevention of recurrent respiratory infections in children. Int J Immunopathol Pharmacol. 2013;26:941-52.

116. La Mantia I, Ciprandi G, Varricchio A, Cupido F, Andaloro C. Salso-bromoiodine thermal water: a nonpharmacological alternative treatment for postnasal drip-related cough in children with upper respiratory tract infections. J Biol Reg. 2018;32(1 Suppl. 2):41-7.

117. Varricchio A, Tricarico D, De Lucia A, Utili R, Tripodi MF, del Giudice M, et al. Inhaled tobramycin in children with acute bacterial rhinopharyngitis. Int J Immunopathol Pharmacol. 2006;19:131-40.

118. Varricchio A, Capasso M, Di Gioacchino M, Ciprandi G. Inhaled thiamphenicol and acetylcysteine in children with acute bacterial rhinopharyngitis. Int J Immunopathol Pharm. 2008;21:625-30.

119. Ciprandi G, Tosca MA. Long-term cetirizine treatment reduces allergic symptoms and drug prescriptions in children with mite allergy. Ann Allergy Asthma Immunol. 2001;87:222-6.

120. Ciprandi G, Cosentino C, Milanese M, Mondino C. Fexofenadine reduces nasal congestion in perennial allergic rhinitis. Allergy. 2001;56:1068-70.

121. Ciprandi G, Varricchio A, Capasso M, Varricchio AM, DeLucia A, Ascione E, et al. Intranasal flunisolide treatment in children with adenoidal hypertrophy. Int J Immunopathol Pharm. 2007;20:833-6.

122. Varricchio A, Tortoriello G, Capasso M, De Lucia A, Marchisio P, Varricchio AM, et al. Prevention of surgery in children with adenoidal hypertrophy treated with intranasal flunisolide: a 12-month follow-up. J Biol Reg. 2009;23:95-101.

123. Varricchio A, Capasso M, De Lucia F, Avvisati AM, Varricchio AM, Bettoncelli $G$, et al. Intranasal flunisolide treatment in patients with non-allergic rhinitis. Int J Immunopathol Pharmacol. 2011;24:401-9.

124. Chong LY, Head K, Hopkins C, Philpott C, Burton MJ, Schilder AG. Different types of intranasal steroids for chronic rhinosinusitis. Cochrane Database Syst Rev. 2016;4:CD011993.

125. Passali D, Spinosi MC, Crisanti A, Bellussi LM. Mometasone furoate nasal spray: a systematic review. Multidisc Respir Med. 2016;11:18.

126. Ciprandi G, Varricchio A. The relevance of the Mometasone Furoate nasal spray device in clinical practice. J Biol Reg. 2018;32:1051-4.

127. Varricchio A, Capasso M, Avvisati F, Varricchio AM, De Lucia A, Brunese FP, et al. Inhaled hyaluronic acid as ancillary treatment in children with bacterial acute rhinopharyngitis. J Biol Reg. 2014;28:537-43.

128. Gelardi M, Taliente S, Fiorella ML, Quaranta N, Ciancio N, Russo C, et al. Ancillary therapy of intranasal T-LysYal ${ }^{\oplus}$ for patients with allergic, nonallergic, and mixed rhinitis. J Biol Res. 2016:30:255-62.

129. Gelardi M, Taliente S, Fiorella ML, Quaranta N, De Candia N, Russo C, et al. Intranasal T-LysYal ${ }^{\oplus}$ as adjunctive therapy in patients after FESS (functional endoscopic sinus surgery). J Biol Res. 2016;30:277-84.

130. Miraglia del Giudice M, Maiello N, Capristo C, Alterio E, Capasso M, Perrone L, Ciprandi G. Resveratrol plus carboxymethyl-b-glucan reduces nasal symptoms in children with pollen-induced allergic rhinitis. Curr Med Res Op. 2014;30:1931-5.

131. Miraglia del Giudice M, Maiello N, Decimo F, Capasso M, Campana G, Leonardi S, Ciprandi G. Resveratrol plus carboxymethyl- $\beta$-glucan may affect respiratory infections in children with allergic rhinitis. Pediatric Allergy Immunol. 2014;25:724-8.

132. Varricchio AM, Capasso M, della Volpe A, Malafronte L, Mansi N, Varricchio A, Ciprandi $G$. Resveratrol plus carboxymethyl- $\beta$-glucan in children with recurrent respiratory infections: a preliminary and real-life experience. It J Pediatr. 2014;40:93.

133. Guerra A, Varricchio A, Ciprandi G. Secondary sinonasal headache in children: an empiric approach. J Biol Reg. 2019;33:1283-7.

134. Varricchio A, DeLucia A, Varricchio AM, della Volpe A, Mansi N, Pastore V, et al. Sinuclean Nebules treatment in children suffering from otitis media with effusion. Int J Ped ORL. 2017;94:30-5.

135. Marseglia GL, Licari A, Ciprandi G. A polycentric, randomized, double-blind, parallel-group, placebo-controlled study on Lertal $^{\circledR}$, a multicomponent 
nutraceutical, as add-on treatment in children with allergic rhinoconjunctivitis: phase I during active treatment. J Biol Reg. 2019;33:617-22.

136. Marseglia GL, Licari A, Leonardi S, Papale M, Zicari AM, Schiavi L, Ciprandi G. A polycentric, randomized, parallel-group, study on Lertal ${ }^{\oplus}$, a multicomponent nutraceutical, as preventive treatment in children with allergic rhinoconjunctivitis: phase II. Ital J Ped. 2019;45:84.

137. Miraglia del Giudice M, Maiello N, Decimo F, Fusco N, D'Agostino B, Sullo N, et al. Airways allergic inflammation and $L$. Reuterii treatment in asthmatic children. J Bio Regulator. 2012;26:35-40.

138. Caffarelli C, Cardinale F, Povesi-Dascola C, Dodi I, Mastrorilli V, Ricci G. Use of probiotics in pediatric infectious diseases. Expert Rev Anti-Infect Ther. 2015; 3:1517-35.

139. Miraglia del Giudice M, Maiello N, Allegorico A, lavazzaro L, Capasso M, Ciprandi G. Lactobacillus reuteri DSM 17938 plus vitamin D3 as ancillary treatment in allergic children with asthma. Ann Allergy Asthma Immunol. 2016;117:710-2.

140. La Mantia I, Varricchio A, Ciprandi G. Bacteriotherapy with Streptococcus salivarius 24SMB and Streptococcus oralis 89a nasal spray for preventing recurrent acute otitis media in children: a real-life clinical experience. Int J Gen Med. 2017;10:171-5.

141. La Mantia I, Varricchio A, Ciprandi G. Is it possible to prevent adenoidectomy? Turk Arch Otolaryngol. 2018;56:129-31.

142. Andaloro C, Santagati M, Stefani S, La Mantia I. Bacteriotherapy with Streptococcus Salivarius 24SMB and Streptococcus Oralis 89a Oral spray for children with recurrent streptococcal Pharyngotonsillitis: A randomized placebo-controlled clinical study. Eur Arch Otorhinolaryngol. 2019;276:879-87.

143. Passali D, Capopello C, Passali GC, Cingi C, Sarafoleanu C, Bellussi LM. Nasal mucociliary transport time alteration: efficacy of 18 B glycyrrhetinic acid. Multidiscipl Respir Med. 2017;12:29.

144. Cavone L, Cuppari C, Mansi S, Grasso L, Arrigo T, Calamai L, et al. Increase in the level of proinflammatory cytokine HMGB1 in nasal fluids of patients with rhinitis and its sequestration by glycyrrhizin induces eosinophil cell death. Clin Exp Otorhinolaryngol. 2025;8:123-8.

145. Damiani V, Camaioni A, Viti C, Scirò AS, Morpurgo G, Gregori D. A singleCentre, the before-after study of the short- and long-term efficacy of Narivent in the treatment of nasal congestion. J Int Med Res. 2012;40:1931-41.

146. Mansi N, D'Agostino G, Scirè AS, Morpurgo G, Gregori D, Gulati A, et al. Allergic rhinitis in children: a randomized clinical trial targeted at symptoms. Indian J Otolaryngol Head Neck Surg. 2014;66:386-93.

147. Licari A, Marseglia G, Ciprandi G. New pharmacologic strategies for allergic rhinitis. Curr Treat Options Allergy. 2016;3:495.

148. Vlastos I, Gkouskou K, Doulaptsi M, Karatzanis A, Prokopakis EP. Precision medicine in rhinosinusitis. Curr Allergy Asthma Rep. 2019;19:12.

149. Ren L, Zhang N, Zhang L, Bachert C. Biologics for the treatment of chronic rhinosinusitis with nasal polyps - state of the art. World Allergy Organ J. 2019;12:100050

150. Glickstein JS, Chandra RK, Thompson JW. Intracranial complications of pediatric sinusitis. Otolaryngol Head Neck Surg. 2006;134:733-6.

\section{Publisher's Note}

Springer Nature remains neutral with regard to jurisdictional claims in published maps and institutional affiliations.

Ready to submit your research? Choose BMC and benefit from:

- fast, convenient online submission

- thorough peer review by experienced researchers in your field

- rapid publication on acceptance

- support for research data, including large and complex data types

- gold Open Access which fosters wider collaboration and increased citations

- maximum visibility for your research: over $100 \mathrm{M}$ website views per year

At $\mathrm{BMC}$, research is always in progress.

Learn more biomedcentral.com/submissions 